\title{
VAGOTOMY IN THE TREATMENT OF PEPTIC ULCER
}

\author{
By C. F. W. ILlingWORTH and A. W. KAY*
}

IN the treatment of peptic ulcer, whether by medical measures or conservative surgical operation, there are two main objectives-to reduce the acidity of the gastric juice and to put the ulcerated part at rest.

Since vagus stimulation is known (Pavlov, I9IO) to bring about the secretion of the "appetite" juice and (Cannon and Washburn, 1912) to enhance the motor activity of the stomach, it seemed reasonable to suppose that these objectives might be attained by division of the vagus nerves.

The operation of vagotomy was introduced by Exner in 1914 for the relief of pain in the gastric crises of tabes and only recently has it been applied (Weinstein et al., 1944; Dragstedt, 1945) in the treatment of peptic ulcer. The object of the present paper is to report the results in a small series in which the denervation was carried out by the abdominal approach.

Surgical Anatomy. - The vagus innervation of the stomach has been described in detail by McCrea (1926). In brief, the vagus fibres as they enter the abdomen through the œsophageal hiatus of the diaphragm are disposed in two main trunks or bundles, one anterior the other posterior. They may communicate in a plexus round the œsophago-gastric junction. From both bundles fibres pass down the lesser curvature and are distributed mainly to the fundus and body of the stomach. From the anterior bundle a distinct branch, the pylorohepatic nerve, passes to the right at a high level in the gastro-hepatic omentum and transmits fibres which reach the stomach along the right gastric and gastro-epiploic arteries. From the posterior bundle, branches pass to the cœliac ganglion and some of these may reach the stomach along the left gastric artery.

Operative Technique.-After division of the left coronary ligament and retraction of the left lobe of the liver, the vagus bundles are divided as they lie on the terminal part of the œsophagus. Since it is difficult to ensure division of all fibres at this point, in our series in addition, denervation was performed at a lower level by the method of Latarjet (1922). This comprises (I) division of the pyloro-hepatic branch as it lies in the gastro-hepatic omentum; (2) division of the main stem of the left gastric artery with its accompanying leash of nerves: this incision is carried down to the submucous coat of the stomach immediately below the cardia on the lesser curvature and

* From the University of Glasgow and the Peptic Ulcer Clinic of the Western Infirmary, Glasgow. 
extended for an inch or so over both surfaces of the stomach; (3) division of all nerve fibres accompanying the right gastric and gastroepiploic arteries.

Clinical Cases.- Since the observations were of an experimental character, it seemed proper to restrict them to a small series of 6 cases. The patients were carefully selected. All had duodenal ulcer; in one there was also a gastric ulcer. All were men of similar ages, all gave a long history of severe indigestion which had resisted or relapsed after one or more periods of careful medical treatment in hospital. All were suffering, at the time of operation, from a severe and prolonged attack (see Table I).

Methods of Investigation. - In addition to a critical assessment of symptoms by repeated examination both before and after operation, the effect of denervation was studied by observations on the gastric motility and secretion.

TABLE I

Vagotomy for Peptic Ulcer

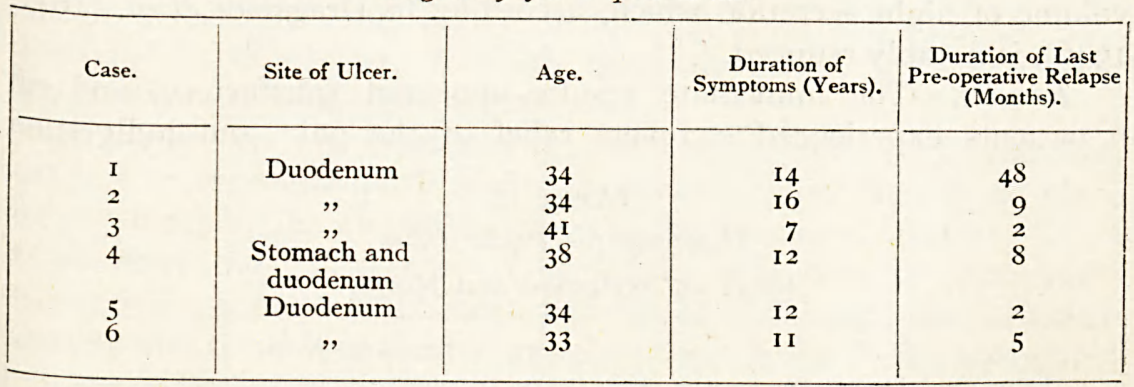

The gastric motility was studied by means of a balloon in the stomach connected with a tambour recording on a kymograph drum, following the technique described by Kay (1947). Records obtained in this way show that the stomach is normally in a state of tone, which remains constant with but small variations. In addition every two or three minutes the stomach undergoes contractions which show themselves as rhythmic waves lasting for perhaps twenty to thirty seconds. In the patient with active duodenal ulcer the tonus variations are more marked and there is a striking increase in the frequency amplitude and duration of the rhythmic contractions.

This was the picture in all 6 cases before operation. After operation there was a striking change, and gastrograms in all cases showed almost complete immobility, with only occasional slight alterations of tone to disturb the calm (Fig. (a)). In 4 cases the effect of parasympathetic stimulation by intravenous injection of $0.5 \mathrm{mgm}$. prostigmine was noted. Before operation this brought about a distinct increase in gastric motility, but after operation was without effect. We interpreted this finding as indicating that the denervation had been substantially complete.

The effect of vagotomy on the acid secretion, on the other hand, 
was slight. In 3 cases there appeared to be some diminution in the volume of juice secreted, but the acid level was practically unchanged. This is in accord with expectation since the hormonal stimulation of acid remains unaffected. Unfortunately no record was made of the

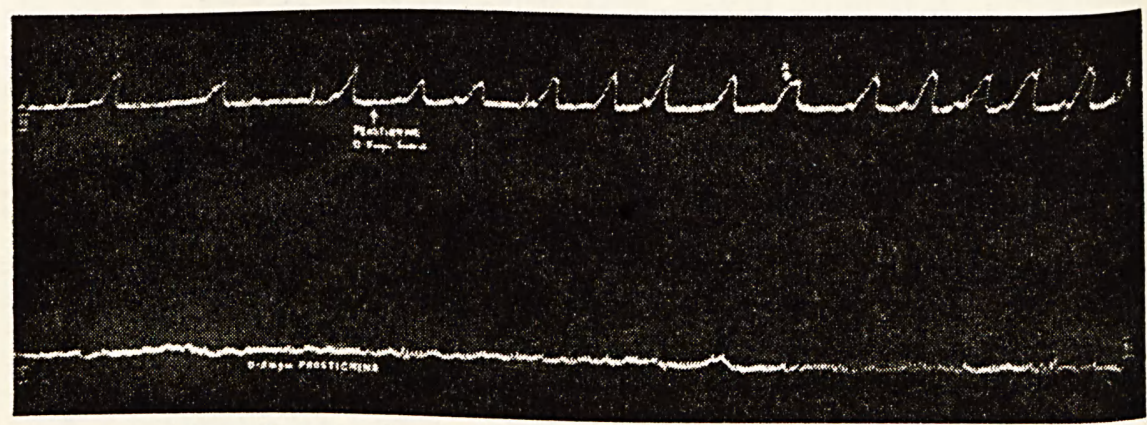

FIG.-Case 2. Gastric Motility (a) before (b) after vagotomy.

volume of night secretion which, according to Dragstedt et al. (1945, 1946), is notably reduced.

Results.-The immediate results appeared satisfactory, and all 6 patients experienced complete relief of the pain and indigestion

TABLE II

Vagotomy for Peptic Ulcer

Effect on Symptoms and Motility

\begin{tabular}{|c|c|c|c|c|c|c|}
\hline \multirow{2}{*}{ Case. } & \multirow{2}{*}{ Pre-operative. } & \multicolumn{5}{|c|}{ Post-operative. } \\
\hline & & Two Weeks. & Six months. & One Year. & Eighteen Months. & Two Years. \\
\hline $\begin{array}{l}\text { I. Symptoms } \\
\text { Motility }\end{array}$ & $+t$ & $\overline{-}$ & - & $\bar{t}$ & $\overline{t+}$ & $\begin{array}{l}+t^{*} \\
++\end{array}$ \\
\hline $\begin{array}{l}\text { 2. Symptoms } \\
\text { Motility }\end{array}$ & $\begin{array}{l}++ \\
++\end{array}$ & $\overline{-}$ & $\overline{-}$ & $\begin{array}{l}- \\
\ldots\end{array}$ & $\begin{array}{l}- \\
\ldots\end{array}$ & $\begin{array}{l}- \\
\ldots\end{array}$ \\
\hline $\begin{array}{l}\text { 3. Symptoms } \\
\text { Motility }\end{array}$ & $\begin{array}{l}+t \\
+t\end{array}$ & - & $\overline{-}$ & $\bar{t}$ & + & $\begin{array}{l}+ \\
\ldots\end{array}$ \\
\hline $\begin{array}{l}\text { 4. Symptoms } \\
\text { Motility }\end{array}$ & $\begin{array}{l}++ \\
++\end{array}$ & $\overline{-}$ & $\begin{array}{l}++^{*} \\
+\end{array}$ & $\begin{array}{l}\cdots \\
\cdots\end{array}$ & $\begin{array}{l}\ldots \\
\cdots\end{array}$ & $\begin{array}{l}\ldots \\
\cdots\end{array}$ \\
\hline $\begin{array}{l}\text { 5. Symptoms } \\
\text { Motility }\end{array}$ & $\begin{array}{l}++ \\
++\end{array}$ & $\overline{-}$ & $\overline{-}$ & $\overline{-}$ & $\overline{-}$ & - \\
\hline $\begin{array}{l}\text { 6. Symptoms } \\
\text { Motility }\end{array}$ & $\begin{array}{l}++ \\
++\end{array}$ & - & $\overline{-}$ & $\overline{-}$ & $\begin{array}{l}++^{*} \\
+\end{array}$ & $\begin{array}{l}\cdots \\
\cdots\end{array}$ \\
\hline
\end{tabular}

* Gastrectomy performed.

from which they had suffered prior to operation. Even making full allowance for the tendency of peptic ulcer to undergo spontaneous remission it did seem that the vagotomy had been effective, and this appears to be confirmed by the fact that 5 of the patients remained symptom-free for eighteen months or more. 
Unfortunately the relief did not prove permanent (Table II). One patient, the case with gastric as well as duodenal ulcer, suffered a relapse within three months; further operation showed that the gastric ulcer had penetrated the pancreas. Gastrectomy was performed and he has remained well since. Two others have required gastrectomy, having relapsed after eighteen months and two years respectively. A fourth patient relapsed after eighteen months but not severely. The remaining two continue symptom-free after three years.

Motility records (Fig. (b)) show that in each case the return of symptoms was preceded by return of motor activity and a positive response to prostigmine. These findings suggest that the recurrence was due to regeneration of the cut nerves. In two cases this was confirmed by microscopic examination after gastrectomy.

\section{Discussion}

The importance, in peptic ulcer, of following the results of treatment over a sufficiently long period before assessing its value is well illustrated in this series, in which the early results were promising but the final outcome quite unsatisfactory.

If we are correct in assuming that the recurrence of symptoms was due to regeneration, it must be concluded that there is no place for vagotomy by the abdominal route in the treatment of ulcer. If, as is possible, the recurrence of symptoms was due to inadequate denervation-some vagal fibres having been missed-the criticism remains that to perform a more complete denervation by the abdominal route would seem to be difficult of achievement and not always to be relied upon.

Although the end-results have been poor, from a broader standpoint the experience has been valuable in indicating the possibility of a different and more widely practicable approach to the ulcer problem. It will be noted that in 5 of our 6 cases prolonged healing of the ulcer, or at any rate prolonged relief of symptoms, was obtained by reducing the gastric motility although the acid level remained unchanged. A similar result may be obtained by the administration of drugs such as atropine, and there would seem to be a field in the future for a search for substances with a similar action but without harmful side effects.

\section{SUMMARY}

In 6 cases of peptic ulcer treated by vagotomy by the abdominal route the immediate effect was to relieve all symptoms. Pain recurred in I case within three months, in 2 cases after eighteen months, and a fourth after twenty-seven months. Recurrence is attributed to regeneration of the cut nerves.

Vagotomy had a pronounced effect in reducing the gastric motility. It had no effect on the acid concentration of the gastric juice. 


\section{REFERENCES}

Cannon, W. B., and Washburn, A. L. (1912), Amer. Journ. Physiol., 29, 44 I. DRAGSTEDT, L. R. (1945), Ann. Surg., r22, 973.

Dragstedt, L. R., and Schafer, P. W. (1945), Surgery, 17, 742.

Dragstedt, L. R., Thornton, T. F., and Storer, E. H. (1946), Journ. Amer. Med. Assoc., r3o, 764 .

Exner, A., and Schwarzmann, E. (I9I4), Mitt. a. d. Grenzgeb d. M. u. Chir., 28, 15 .

KAY, A. W. (1947), Lancet, r, 448.

Latarjet, A. (1922), Bull. de l'Acad. de Med., 87, 681.

MCCREA, E. D'A. (1926), Brit. Journ. Surg., r3, 621.

Pavlov, I. (1910),"The Work of the Digestive Glands (English translation). (Griffin \& Co., London.)

Weinstein, V. A., Colp, R., Hollander, F., and Jemerin, E. E. (1944), Surg. Gynac. and Obstet., 79, 297. 